\title{
Língua portuguesa, quinto império e sebastianismo: Pessoa leitor de Bandarra
}

\author{
Carlos Alberto Pasero \\ Universidade de Buenos Aires
}

A José Emilio Burucúa

Loing de sa terre Roy perdra la bataille, Prompt eschappé poursuivy suivant prins, Iguare prins soubs la dorce maille, Soubs fainct habit \& l'ennemy surprins.

Nostradamus, VI, 14

A alma portuguesa está grávida de divino.

Fernando Pessoa

\section{Introdução}

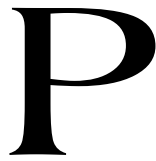

arte da obra de Fernando Pessoa, tanto em prosa como em verso, ${ }^{1}$ constitui um palco de reflexão e reelaboração de um imaginário nacionalista coletivo, pensado no marco da conjuntura específica de Portugal nas primeiras décadas do século XX. O contexto português de então registrava o fracasso da experiência republicana,

${ }^{1} \mathrm{O}$ livro Mensagem (1934) de Fernando Pessoa constitui a parte principal de sua obra político-poética com base ocultista. V. COELHO, Jacinto do Prado. O nacionalismo utópico de Fernando Pessoa. Colóquio/Letras, Lisboa, n. 31, p. 53-57, dez. 1964. LIND, Georg Rudolf. Elementos ocultistas na poesia de Fernando Pessoa. Colóquio/Letras, Lisboa, n. 37, p. 60-63, fev. 1966. GONÇALVES, Maria Madalena. Significados retóricos de um mito nacional. D. Sebastião n'O Desejado de Nobre e na Mensagem de Pessoa. Colóquio/Letras, Lisboa, 
a impossibilidade de superar estruturas de atraso agrícola e decadência e os intentos de corporizar, na figura de um líder forte e indiscutível, a renascença da nação, em sintonia com os regimes da Itália, primeiro e da Alemanha, depois. Nesse contexto, as soluções nacionalistas tendem a se assemelhar. Não obstante, respondem a interesses diversos ou assumem projetos mais ou menos próximos ao interesse hegemônico. Pessoa, como ideólogo político, em consonância com o ideário conservador, antidemocrático e monárquico, tenta uma reformulação nacionalista ancorada no passado português, a mística esotérica e a messiânica popular. Não obstante, a miúdo, costuma-se atenuar e desculpar os alcances políticos da proposta pessoana, sobretudo, seu extremismo ideológico e os aspectos "politicamente incorretos" de sua expressão mental. O projeto pessoano fica, assim, às vezes, afastado do irracionalismo político, ao qual pertence, em que costuma-se interpretar o destino nacional fortemente ligado ao profetismo e a religiosidade. Além do mais, esse pensamento, no caso de Pessoa e de outros nacionalistas portugueses, abreva numa fonte primordial da cultura popular, as Trovas de Bandarra. Pessoa político é, também, leitor principal de Bandarra e, ao mesmo tempo, leitor de um gênero específico de literatura popular, a profecia. ${ }^{2}$

n. 113/14, p. 91-98, jan.-abr. 1990 e DAL FARRA, Maria Lúcia. Notas parta uma futura compreensão do sebastianismo na Mensagem de Pessoa. AA. VV., 1998, p. 81-94. Pedro Texeira da Mota recolheu textos pessoanos de caráter místico e nacionalista em PESSOA, 1989.

${ }^{2}$ A profecia, como é sabido, remete à tradição judeu-cristã, por uma parte, e à tradição pagã greco-latina. Constitui um gênero que se entrelaça com a prática astrológica e a mística bỉblica. Cfr. WARBURG, Aby. La rinascita del paganesimo antico. Contibuti alla storia della cultura. Trad. Emma Cantimori. Florença: La Nuova Italia Editrice, 1966. ZAMBELI, Paola. "Astrologi hallucinati". Stars and the End of the World in Luther's Time. Nova Iorque: Walter de Gruyter, 1986. COHN (En pos del milenio. Revolucionarios milenaristas y anarquistas misticos de la Edad Media. Barcelona: Barral, 1972.) salienta que, não obstante a tradição apocalíptica ser rejeitada pela doutrina oficial católica, "siguió influyendo en el oscuro mundo de la religión popular" (p. 29). Na poesia popular brasileira o profetismo sobrevive ainda na "literatura de cordel", penetrada de astrologia, sebastianismo e milenarismo, como pode se apreciar, por exemplo, em J. Barros, Profecias do Padre Cícero Até o Ano Dois Mil ou Abraão Batista, As professias sobre o Papa e o fim do mundo e na série de 
Em princípio, é preciso salientar que a lingua portuguesa é veículo da profecia nacional. Um aspecto interessante é a dimensão oferecida por Pessoa ao espaço lingüístico, no marco do seu projeto imperial. Neste sentido, perguntamo-nos: Qual é o imaginário lingüístico traçado por Pessoa em relação à leitura de Bandarra e à profecia do Quinto Império? De que maneira Pessoa lê Bandarra? Como interpreta o destino português, tanto para o passado como para o futuro? O contexto cultural português fornece certa predisposição para uma leitura messiânica da política. O pensamento de Pessoa é a retomada de uma longa tradição profética, que nasce com os mestres bíblicos e acaba se relacionando com a doutrina ocultista popular ou propagandista. Mas que, no contexto específico português, encarna-se na prédica bandárrica e no fenômeno político e religioso do sebastianismo. Pessoa escreve:

O que significa, ao certo, essa Vinda de D. Sebastião? O próprio D. Sebastião o que significa? Perguntas são estas a que se não pode responder senão como o texto velado do Tertuliano: Aquelas coisas que estão veladas, descobertas, ficam destruídas. ${ }^{3}$

A estas perguntas, não obstante, tem procurado responder Pessoa em seus textos políticos desde uma posição que entrelaça a cultura popular, a cosmovisão esotérica e a sua própria concepção da criação poética e da linguagem.

almanaques de Manoel Caboclo e Silva, Almanaque OJuizo do Ano para o Nordeste. Cf. Lopes, Régis. João de Cristo Rei. Oprofeta de Juazeiro. Fortaleza: Secretaria de Cultura e Desporto do Estado do Ceará, 1994. Sobre o cordel brasileiro: Slater, Candace. A vida no barbante. A literatura de cordel no Brasil. Rio de Janeiro: Civilização Brasileira, 1984.

${ }^{3}$ PESSOA, 1978. p. 193. Neste livro recolhem-se textos políticos de Fernando Pessoa, todos concebidos no marco de uma fé messiânica e nacionalista. Para os fins deste trabalho, centramo-nos nos textos mais significativos, que constituem a terceira e quarta parte do livro, Quando regressa D. Sebastião? e Portugal - Quinto Império (p. 139 a 256). 


\section{Bandarra e o sebastianismo}

Na sua leitura de Bandarra, Pessoa consuma um ato de convergência cultural, com antecedentes na cultura portuguesa, mas que culmina num máximo de ineditismo e potencialidade criadora. ${ }^{4}$ Ora bem, embora a obra de Pessoa seja, por sua mesma monumentalidade, uma estrutura complexa de convergências, ao menos no ângulo em que se interceptam o populare o culto, a cultura de elite e a cultura do povo, poderia oferecer caminho de abordagem, especialmente para o problema moderno da heteronimia. Pessoa exemplificaria, neste sentido, o que Burucúa (2001), em sentido platônico-erasmiano, chama de "silenos", isto é, aqueles sujeitos que contribuem à circulação cultural portando idéias, experiências ou práticas culturais entre diversos horizontes sociais. Explica Burucúa:

Los intermediarios culturales también se comportan como silenos, cuerpos extraños, risibles, a veces repulsivos en los medios sociales de donde proceden o donde actúan, pero portadores de un pequeño tesoro (el de alguna creación impregnada de la experiencia de la alteridad cultural) que ellos desean transmitir a sus semejantes de antaño a los de hogaño.

Burucúa classifica os "silenos" em três categorias: uma primeira classe a conformariam aqueles mediadores que "salen del mundo del pueblo y se dirigen al mundo de las élites". Burucúa batizá-los como "Anfiones". "Buenos ejemplos de nuestros Anfiones, diz Burucúa, son Rabelais, Milton, Blake, T.H. Lawrence, Truman Capote y José María Arguedas." Uma segunda categoria a constituem os que "salen del mundo de la élites y se dirigen al mundo del pueblo." São de dois tipos: os

\footnotetext{
${ }^{4}$ Levamos em consideração a abordagem de CHARTIER (El mundo como representación. Historia cultural: entre práctica y representación. Barcelona: Gedisa, 1999) no tocante ao estudo dos objetos impressos e a história das práticas de leitura. CHARTIER focaliza o impresso e a sua circulação como apropriável de maneira diferenciada, valorada assimetricamente, em relação com os diversos lugares sociais. Para CHARTIER, a participação tradicional entre o culto e o popular deve ser questionada. Diz CHARTIER: "En ambos casos, lo popular se define por su diferencia con algo que no es él (la literatura erudita y letrada, el catolicismo normativo de la iglesia); en ambos casos, el historiador ('intelectual' o 'cultural') tiene ante sí un cuerpo bien diferenciado del cual debe inventariar los motivos." ( p. 34).
} 
"Prometeos", os que procuram libertar como Saint-Just, Byron ou Tolstoi e "Los prófugos de Arcadia", isto é, aqueles mediadores que como Perrault ou Grimm são "los nostálgicos de un pasado idealizado que se pierde". Uma terceira e última categoria de "silenos" são "Los mediadores que salen del mundo del pueblo, circulan por el mundo de las élites y permanencen sin embargo en el horizonte cultural de origen. ${ }^{5}$ Burucúa cita como exemplos os sapateiros políticos, Menocchio e o carteiro Cheval, entre outros. Pessoa como intermediário ou demiurgo social, não obstante, é de classificação difícil. Participa um pouco de cada um dos tipos traçados por Burucúa; mas, é claro que pertence fundamentalmente à classe dos mediadores surgidos da elite e que dirigem-se ao povo. No caso de Pessoa, um pouco como libertador e outro pouco como saudoso. O que representa a contradição entre o projeto modernista e o peso da mítica nacional.

Como é sabido, a tradição bandárrica remonta-se a Gonçalo Anes Bandarra, sapateiro natural de Trancoso, nascido perto do ano de $1500 .{ }^{6}$ Como o indicara Burke (1996), a obra de Bandarra inscreve-se numa série maior, do ponto de vista social, a "cultura de los zapateros".

El prototipo del zapatero filósofo, diz Burke, tiene una tradición que llega, cuanto menos, al tiempo de Luciano en el siglo II, pero es fácil encontrar verdaderos ejemplos de zapateros quienes durante la época moderna no permanecieron fieles a la religión oficial, prefiriendo abrazar la herejía?

Burke lembra os casos de outros dois sapateiros portugueses profetas, entre outros nomes europeus em geral, Luís Dias de Setúbal e Simão Gomes. Pelo que pode-se inferir de seu processo inquisitorial, ${ }^{8}$ Bandarra era um artesão

\footnotetext{
${ }^{5}$ BURUCÚA, 2001. p. 37.

${ }^{6}$ Sobre o tema seguimos basicamente BESSELAAR, 1986 e REAL, 1998. Temos levado em consideração, também: SERRÃO, Joel. Dicionário de História de Portugal. Porto: Figueirinhas, 1981. PIRES, António Machado. D. Sebastião e o Encoberto. Lisboa: Fundação C. Gulbenkian, 1982. SARAIVA, António José. A cultura em Portugal. Teoria e história. Introdução geral à cultura portuguesa. Lisboa: Gradiva, 1994.

${ }^{7}$ BURKE, 1996. p. 80.

${ }^{8}$ Segundo BESSELAAR, 1986, o processo foi publicado por Teófilo Braga na sua História de Camões, 1873.
} 
e comerciante próspero, leitor da Bỉblia, que mantinha correspondência com vários personagens importantes de Portugal. O caráter letrado de Bandarra era uma característica tradicional do grupo dos sapateiros. ${ }^{9}$ Sabia de cor longas passagens do Velho Testamento. "Assim, diz van der Besselaar, ele acabou passando por oráculo em assuntos bíblicos, sobretudo entre os cristãos-novos, que eram muito numerosos na Beira." ${ }^{10}$ Tinha conhecimento das profecias atribuídas a Santo Isidoro e estava muito imbuído do sonho joaquimista do estabelecimento de uma monarquia mundial, em prol de desbaratar o poder muçulmano.

O componente messiânico das Trovas de Bandarra encontrou especiais ouvintes na comunidade de judeus conversos e cripto-judeus. As relações entre Bandarra e os judeus portugueses eram, seguramente, comerciais. Sobre essa base teriam-se acentuado os laços religiosos e ideológicos, em virtude de compartilhar uma mesma visão do mundo e um mesmo conjunto de interesses sociais e políticos. Isto alarmou a Inquisição, que prendeu Bandarra em 1540. "Bandarra profetiza aos judeus da Beira e, depois, através de Heitor Lopes, aos judeus portugueses, o anúncio do Messias e a consumação para breve do Quinto Império." ${ }^{11}$ A Inquisição impôs como castigo a Bandarra abjurar de suas Trovas, não obstante, não ser acusado de judaísmo.

O que se lhe imputava era causar alvoroço entre os cristão-novos com as suas trovas, que eles tendiam a interpretar em sentido judaico; além disso, causava suspeita que ele, homem 'sem letras', se arvorava em intérprete da Sagrada Escritura. ${ }^{12}$

A leitura judaica das Trovas, porém, continuaria em representação de interesses políticos e econômicos do grupo de negociantes e de aqueles ligados aos interesses contrários ao monopólio espanhol e o controle inquisitorial, além das fronteiras de Portugal. A crença bandárrica constitui,

\footnotetext{
${ }^{9}$ Pergunta-se BURKE, 1996. p. 81: “QQué tenía que ver el hacer zapatos con la herejía o la revolución? Quizá es posible que se debiera a que esta actividad sedentaria ofrecía tiempo libre para reflexionar sobre la vida, un verdadero equivalente urbano del pastor de ovejas."

${ }^{10}$ BESSELAAR, 1986. p. 15.

${ }^{11}$ REAL, 1998. p. 123.

${ }^{12}$ BESSELAAR, 1986. p. 15.
} 
segundo Real (1998), a resposta popular à ancilose do pensamento filosófico oficial. A isto, "replica o povo com o nascimento de uma crença no aparecimento de um Encoberto messiânico, redentor das energias pátrias e regenerador das antigas venturas que tinham feito grande o Império Português."13

Após a derrota e sumiço do rei Dom Sebastião, o conteúdo da Trovas de Bandarra adquire seu caráter sebástico. ${ }^{14} \mathrm{~A}$ humilhação nacional produzida pela perda da independência gerou

por compensação psicológica 'as maravilhas teológico-patriotas' de Bernardo de Brito sobre a fundação divina de Portugal, desde logo enquadradas na História do Futuro de padre António Vieira e popularmente atiçadas pelas Trovas de Bandarra. ${ }^{15}$

O sebastianismo encontrou na obra do padre Vieira importante desenvolvimento ideológico em favor da restauração bragantina. ${ }^{16}$ Diz Vieira em seu Discurso em que se prova a vinda do Senhor Rei D. Sebastião: "Provar a vinda do sereníssimo Rei D. Sebastião o qual se conserva vivo, a pesar dos que o querem morto..."17 A esse respeito Novinsky assinala:

${ }^{13}$ REAL, 1998. p. 121.

14 "De hecho, la transformación ocurrida desde 1580 hasta el inicio del siglo XVIII provocó un profundo traumatismo en la memoria nacional. Esta enorme conmoción coincidió con una modificación de la propia estructura social y marca los inicios de un sebastianismo que reaparece una y otra vez. El sebastianismo, que es explicado normalmente como el deseo de retorno a un glorioso pasado nacional, es simultáneamente la expresión de la añoranza de una sociedad desaparecida. La derrota de Alcazarquivir es la derrota de un cierto tipo de nobleza." PEREIRA, Miriam Halpern. "Decadencia" o subdesarrollo: una reinterpretación de sus orígenes en el caso portugués. Política y economía. Portugal en los siglos XIX y XX. Barcelona: Ariel, 1984. p. 89.

${ }^{15}$ REAL 1998. p. 22-3.

${ }^{16}$ Cf. CANTEL, Raymond. Prophétisme et messianisme dans l'Ouvre d'António Vieira. Paris: E. Hispano-Americanas, 1960.

${ }^{17}$ VIERA, 1998. p. 111. Cf. VIEIRA, António. Obras escolbidas. Prefácio e notas A. Sérgio e H. Cidade. Lisboa: Sá da Costa, 1951 e VIEIRA, António. História do Futuro. Introducção, texto e notas Mํㅡ. L. Carvalhão Buescu. Lisboa: Imprensa Nacional - Casa da Moeda, 1982. 
A Restauração do trono português, assim como a sua [de Vieira] concepção do Quinto Império estavam ligadas aos judeus. Materialmente a guerra de Portugal contra a Espanha estava sendo sustentada por judeus portugueses, principalmente por Duarte da Silva, e da Holanda mandavam pólvora, armas, munições para a defesa do país. Essas ações eram coordenadas por cristãos-novos radicados em Portugal. Para Vieira, o Quinto Império dependia do regresso das Tribos Perdidas à Terra Prometida e da filiação do povo judeu ao povo português. ${ }^{18}$

O messianismo e o saudosismo penetraram profundamente no pensamento português, por causa daqueles acontecimentos pouco felizes ligados à perda da independência, os quais geraram, finalmente e em contrapartida, um posicionamento nacionalista e religioso. ${ }^{19} \mathrm{O}$ problema tem ocupado destacados pensadores portugueses, crentes ou cépticos, como Agostinho da Silva, Teixeira de Pascoaes, António José Saraiva, Eduardo Lourenço ou Jorge Dias, até nossos dias. O ambiente que envolveu Pessoa, a princípios do século XX, esteve abonado, precisamente, por Teixeira de Pascoaes, que defendia uma concepção providencialista da história de Portugal e procurou a renascença do ideal sebastianista de uma pátria gloriosa, assim como a volta ao culto priscilianista primitivo português.

18 NOVINSKY, Anita. Sebastianismo, Vieira e o messianismo judaico. AA. VV., 1998. p. 74. Sobre o pensamento messiânico de Vieira veja-se: SILVEIRA, Francisco Maciel. Sermão pelo bom sucesso das armas de Portugal contra as de Holanda. O futuro do passado. Colóquio / Letras. Lisboa, n. 74, p. 29-36, jul. 1983.

${ }^{19} \mathrm{O}$ contexto espiritual que levou a alimentar a fé messiânica na volta do rei morto (hipoteticamente vivo e oculto) aparece magistralmente descrito na História de Portugal (1879) de Oliveira MARTINS (14. ed. Lisboa: Guimarães Editores, 1964. p. 369): "Os profetas, o Bandarra, e Simão Gomes, o sapateirosanto, inspirados, cantavam a epopeia do herói, e as condições em que viria a aparecer para redimir o seu povo: como na Judeia, também, o Cristo fora um salvador da nação, antes de ser redentor das almas. Também o Cristo português havia de alargar o seu império por longes terras, e a sua idade seria a era de redenção. Também o messianismo da Judeia fora buscar às lembranças próximas do reinado glorioso de Hircano a raiz positiva da formação aérea - como a pessoa do imberbe príncipe desgraçado era a raiz do edifício místico português." 
... além de conter o núcleo de uma sensibilidade muito esparsa no primeiro quartel do século, o saudosismo pascoalino é muito (e nem sempre polemicamente) sensível em F. Pessoa, que foi aliás seu teorizador em A Águia, e nos presencistas... ${ }^{20}$

Um outro autor que reivindicou o sebastianismo foi Afonso Lopes Vieira, que, em 1905, fez conhecer seu livro O Encoberto. Um ano antes, com o mesmo título, Sampaio Bruno publicou um ensaio no qual propõe, como símbolo de toda a humanidade, a D. Sebastião. Eis o contexto no qual Pessoa promove, a partir dos textos que publicava na revista Águia, a chegada de um Supra-Camões. A base fundamental de destas teorias providencialistas é, explica Miguel Real, a preeminência do passado como base do futuro, "como serpente mordendo a sua própria cauda desdobra imageticamente a História de Portugal numa espiral repetitiva de mesmidade..."

\section{Língua portuguesa e império do espírito}

O motor principal da reflexão de Pessoa é um tema recorrente no pensamento português, a decadência. ${ }^{22}$ Sobre a decadência de Portugal, temse interessado Camões, o padre António Vieira, Antero de Quental, Oliveira Martins, Eça de Queirós e os saudosistas. A reflexão sobre a decadência costuma assimilar ou aproximar Portugal com Israel. A aproximação, superficialmente, relaciona-se com a Cristandade, na medida em que Portugal pensa-se como Terra Santa e os portugueses como o outro povo, o novo, escolhido de Deus. Mais profundamente, porém, se teria que levar em consideração também a possibilidade de existir uma analogia entre a diáspora dos judeus, após a destruição do Templo de Jerusalém, e o perigo de perda ou anulação que ameaça a nação portuguesa, além da quase diáspora gerada com as descobertas. Nesta analogia ficam implícitos, sem dúvida, também, os fortes componentes hebraicos da cultura portuguesa. ${ }^{23}$

${ }^{20}$ SARAIVA E LOPES, 1996. p. 966.

${ }^{21}$ REAL, 1998. p. 57.

22 Sobre o tema da decadência v. PIRES, António Machado. A ideia de decadência na Geração de 70. Lisboa: Vega, 1992.

${ }^{23}$ Cfr SARAIVA, António José. A cultura em Portugal. Teoria e história. Introdução geral à cultura portuguesa. Lisboa: Gradiva, 1994. 
A leitura de Bandarra feita por Pessoa está, em parte, mediada pela leitura do padre Vieira. ${ }^{24}$ Pessoa tinha grande admiração por Vieira, não obstante percorra, no tocante aos resultados, outros caminhos interpretativos no marco da fé sebástica, mas não naquilo que tem a ver com a semiose posta em prática. Ao referir-se ao Quinto Império, numa interpretação portuguesa, para Pessoa trata-se de um império do espírito. Diz Pessoa:

A chave está dada, clara e obscuramente, na primeira quadra do Terceiro Corpo das Profecias do Bandarra, entendendo-se que Bandarra é um nome coletivo, pelo qual se designa, não só o vidente de Trancoso, mas todos quantos viram, por seu exemplo, à mesma Luz. Este Terceiro Corpo não é, nem poderia ser, do Bandarra de Trancoso. Dizemos, contudo que é do Bandarra. ${ }^{25}$

Considerar Bandarra, no Terceiro Corpo das Trovas, um heterônimo coletivo $^{26}$ lembra a conhecida carta dirigida a António Casais Monteiro, do 13 de janeiro de 1935, na qual Fernando Pessoa explica, detalhadamente, a gênese de seus heterônimos: "Eu vejo diante do incolor mas real do

${ }^{24}$ Sobre sebastianismo e profetismo no padre Vieira consultamos: BESSELAAR, José van den. António Vieira: o homem, a obra, as ideias. Lisboa: Instituto de Cultura e Língua Portuguesa, 1986. BOSI, Alfredo, Vieira e o reino deste mundo e PÉCORA, Alcir, O processo inquisitorial de Antônio Vieira. AA. VV. 1998, p. 13-48 e p. 49-64 respectivamente. Sobre a obra do padre Vieira: SARAIVA e LOPES, 1996, p 517-32. CASA NOVA, Vera Lúcia de Carvalho. Vieira: uma lição de retórica. DUARTE, Lélia Parreira. Ambigüidade nos Sermões de Vieira: dar a César ou a Deus? FREITAS, Marcus Vinícius de. O discurso colonial: notas sobre o Padre Antônio Vieira. OLIVEIRA, Paulo Motta. A recepção de Vieira por Garrett, Camilo e Teófilo. OLIVEIRA, Silvana Maria Pessôa de. Antônio Vieira: a palabra empenhada e SCARPELLI, Marli de Oliveira Fantini. A superposição de espelhos na retórica de Vieira. Boletim do Centro de Estudos Portugueses, Belo Horizonte, v.18, n.22 , p. 11-86, jan./jun. 1998.

${ }^{25}$ PESSOA, 1978. p. 247.

26 "É Bandarra um nome colectivo, insiste Pessoa, e designa, não um só homem, o primeiro português que teve a visão profética dos destinos do país, senão também aqueles outros, que se lhe seguiram, e que, servindo-se do seu tipo de visão e da sua forma literária, buscaram legitimamente o anonimato designando as suas trovas como sendo do Bandarra também." PESSOA, 1978. p. 175. 
sonho, as caras, os gestos de Caeiro, Ricardo Reis e Álvaro de Campos. Construí-lhes as idades e as vidas. (...) A simulação é mais fácil até porque é mais espontânea, em verso." A heteronímia pessoana não só tem a ver com a sua própria obra ou com a concepção de Bandarra como autor coletivo senão com o "mesmo Deus que criou este Mundo não é porventura mais que um de muitos 'deuses', criador de um de muitos 'universos', misteriosamente coexistentes, todos eles porventura descriptíveis como infinitos e eternos." ${ }^{27}$ É preciso salientar que Pessoa interessou-se especialmente no Terceiro Corpo das Trovas justamente pela gênese coletiva destas. Além do mais, o Quinto Império assume-se como mito nacional. "É que desse modo se pretende que ele funcione como um 'heterónimo' da Pátria sucumbida ..." ${ }^{28}$

Em relação com os destinos de Portugal e as profecias, Pessoa levou em consideração, além de Bandarra, os vaticínios do monge Napolitano, o monge Rolando, São Dâmaso Português, Frei Alonso Cavalheiro, Frei Cristovão e o padre António Vieira. Deste último transcreve: "Allá verrá de Lixbona / Uma illustre persona, / Cuja fama já resona / Por toda a parte e lado / En el mundo dará gram brado." Conhece e leva em consideração Nostradamus, a quem faz coincidir, e quanto ao regresso de Dom Sebastião, com Bandarra. E com respeito a este último salienta seu caráter nacional e exclusivamente de interesse português já que se refere a três temas, o Quinto Império, a ida e a volta de Dom Sebastião e os destinos da pátria portuguesa. O Quinto Império é concebido por Pessoa como um império de síntese do espírito português do espírito universal. ${ }^{29}$ Será aquele que faça a síntese do Império Grego, do Império Romano, do Império Cristão e do Império Inglês. "E assim, passados os quatro /Tempos do ser que sonhou, / A terra será teatro / Do dia claro, que no atro / Da erma noite começou." (Mensagem, O Quinto Império). O Quinto Império é também síntese dos sentidos intelectual e místico, conjunção de racionalidade e intuição mágica, que, numa progressão analógica, própria do pensamento ocultista de Pessoa, implica a reunião do masculino e do feminino:

\footnotetext{
${ }^{27}$ PESSOA, 1978. p. 146.

${ }^{28}$ SERRÃO, 1981. p. 41.

${ }^{29}$ V. SIMÕES, 1996, "El mito del Quinto Imperio", p. 459-69.
} 
Assim temos que no Quinto Império haverá a reunião das duas forças separadas há muito, mas de há muito aproximando-se: o lado esquerdo da sabedoria - ou seja, a ciência, o raciocínio, a especulação intelectual; e o seu lado direito - ou seja, o conhecimento oculto, a intuição, a especulação mística e kabalística. ${ }^{30}$

O Quinto Império, destino de Portugal, tornará universal a civilização européia. Neste conceito entrelaçam-se a leitura de Vieira, o patriotismo nacionalista e a especulação cabalística, tal como pode-se conferir no livro Mensagem de 1934, "en perfecto acuerdo con la aspiración más profunda y más íntima de la personalidad del poeta: la esperanza en el futuro, el mesianismo del regreso al paraíso perdido." ${ }^{1}$ Em virtude de que, para Pessoa, "uma nação chega a seu auge de grandeza quando realiza plenamente o seu imperialismo específico". ${ }^{32} \mathrm{O}$ destino português, como forma de superação da decadência, consiste em assumir a missão de um imperialismo de cultura. Precisamente, o sucesso português da época de ouro, o século XVI, baseou-se no caráter cultural e científico das descobertas. "Portugal surgiu definitivamente na civilização européia pelas descobertas ... a nossa primeira descoberta foi descobrir a idéia de descoberta." 33 Segundo Pessoa existem três tipos de imperialismos, o imperialismo de domínio, o imperialismo de expansão e o imperialismo de cultura. Uma civilização evolui através destes três estágios. O problema é saber se Portugal pode assumir o papel de uma grande potência espiritual. A resposta é afirmativa porque "a primeira coisa em que Portugal se tornou notável na atenção da Europa foi um fenômeno literário (...) a poesia dos Cancioneiros" e "os romances de cavalaria". Além do mais, "Portugal surgiu definitivamente na civilização européia pelas descobertas, e as descobertas são um acto cultural, são um acto de criação civilizacional." Já que "Portugal é o único em que o tipo superior de mentalidade teve progresso, que não regresso, do princípio do século dezanove para cá." ${ }^{44}$ Os marcos mentais de Pessoa assemelham-

\footnotetext{
30 PESSOA, 1978. p. 146.

31 SIMÕES, 1996. p. 465.

32 PESSOA, 1978. p. 220.

33 PESSOA, 1978. p. 223.

${ }^{34}$ PESSOA, 1978. p. 223.
} 
se, como salienta Simões (1996), ao fascismo, embora Pessoa não possa se filiar estritamente a essa corrente política. Não obstante, todos seus traços formam parte de um sistema afim aos delírios ocultistas do entorno nazi ou aos fumos idealistas da mística voluntarista mussoliniana. Essas ideologias de extrema direita e o conservadorismo de Pessoa coincidiam, sobretudo, para um mesmo fim, "Reduzir o proletariado tanto quanto possível à situação dos escravos. Fazer isto de modo disfarçado, cauto, íntimo. A plebe deve ser o instrumento dos imperialistas..." 35

\begin{tabular}{|c|c|c|c|c|c|c|c|c|}
\hline \multicolumn{9}{|c|}{ IMPERIALISMOS } \\
\hline \multicolumn{3}{|c|}{ DOMÍNIO } & \multicolumn{3}{|c|}{ EXPANSÃO } & \multicolumn{3}{|c|}{ CULTURA } \\
\hline Unificador & Cesarista & Hegemônico & $\begin{array}{l}\text { Colonizador } \\
\text { de desertos } \\
\text { ou raças } \\
\text { incivilizáveis }\end{array}$ & $\begin{array}{c}\text { Aproveitador } \\
\text { de raças } \\
\text { decadentes }\end{array}$ & $\begin{array}{c}\text { Dominador } \\
\text { de raças } \\
\text { civilizadas } \\
\text { mas fracas } \\
\text { ou menos } \\
\text { civilizadas }\end{array}$ & $\begin{array}{c}\text { Imperialismo } \\
\text { de expansão } \\
\text { espiritual }\end{array}$ & $\begin{array}{c}\text { Criador de } \\
\text { novos valores } \\
\text { civilizacionais } \\
\text { para acordar } \\
\text { nações }\end{array}$ & $\begin{array}{c}\text { Dominador ou } \\
\text { colonizador } \\
\text { que civiliza } \\
\text { ou modifica } \\
\text { raças } \\
\text { indígenas, } \\
\text { inferiores, } \\
\text { decadentes ou } \\
\text { menos } \\
\text { civilizadas } \\
\end{array}$ \\
\hline Ex. Prussia & Ex. Roma & $\begin{array}{c}\text { Ex. Áustria } \\
\text { e Espanha }\end{array}$ & & $\begin{array}{l}\text { Ex. Inglaterra } \\
\text { em Egito e } \\
\text { Índia }\end{array}$ & & Ex. França & $\begin{array}{l}\text { Ex. Grécia } \\
\text { e Portugal }\end{array}$ & Ex. Inglaterra \\
\hline
\end{tabular}

Com respeito ao sebastianismo, Pessoa rejeita dois posicionamentos, afins mas diferenciados. Um, o daqueles que depreciam o sebastianismo por tratar-se de uma “... mera superstição popular...” e o outro, o daqueles que consideram o sebastianismo como um "...devaneio imperialista da decadência...". ${ }^{36}$ Pessoa tinha em mente o livro do padre José Agostinho de Macedo, Os Sebastianistas. Reflexões críticas sobre esta ridicula seita (1810). Oposto ao racionalismo e humanismo universalistas, Pessoa concebe a figura de Bandarra da mesma maneira como assume sua própria produção heterônima, isto é, numa concepção muito particular do sujeito, de evidente raiz ocultista, romântica e nacionalista.

35 PESSOA, 1978. p. 226.

36 PESSOA, 1978. p. 190. 
Pessoa contrapõe o Bandarra histórico com um Bandarra coletivo e oculto, assim como contrapõe um $D$. Sebastião histórico com um $D$. Sebastião coletivo e oculto. Nas razões ocultas radica o caráter coletivo de um sujeito espiritual. O histórico é o visível enquanto só o oculto pode transformar a mera individualidade numa entidade popular e coletiva. O estatuto da política fica ancorado neste último estágio, quando uma força espiritual encarna os desejos da nação. Para Pessoa o Sebastianismo é, neste sentido, obscuro, isto é, esotérico, ${ }^{37}$ mas não desprezível já que "o sebastianismo é o único movimento profundamente nacional". Esta última é a razão exotérica. Este movimento nacional opõe-se aos movimentos anti-nacionais:

\begin{tabular}{|c|c|}
\hline MOVIMENTOS NACIONAIS & MOVIMENTOS ANTI-NACIONAIS \\
\hline $\begin{array}{l}\text { - “...o sebastianismo é o único movi- } \\
\text { mento profundamente nacional que } \\
\text { tem havido entre nós, tendo toda a força } \\
\text { de um movimento religioso, que é, e } \\
\text { todo aquele cunho nacional que falta a } \\
\text { todos os movimentos políticos entre }\end{array}$ & $\begin{array}{l}\text { - “... o catolicismo (outro dos elementos } \\
\text { estrangeiros entre nós existente e inimigo radical } \\
\text { da Pátria)...” } \\
\text { • SÉCULO XVIII: “... mimetismo da Grande } \\
\text { França absolutista feito pelo Marquês do } \\
\text { Pombal...” } \\
\text { • SÉCULO XIX: “... [a] servil cópia do cons- } \\
\text { titucionalismo inglês realizada esterilmente } \\
\text { pelos nossos 'liberais'...” } \\
\text { • SÉCULO XX: “... [a] reles subserviência aos } \\
\text { ideias da Revolução Francesa, estrangeiros para } \\
\text { nós, que são uma das coroas da inglória e do } \\
\text { antipatriotismo do nossos pseudo- } \\
\text { republicanos de hoje em dia.” (p. 191) }\end{array}$ \\
\hline
\end{tabular}

Retomando, de alguma maneira, a proposta saudosista de voltar a uma religiosidade primitiva, Pessoa propõe adotar o sebastianismo como religião nacional. ${ }^{38}$ Diz Pessoa: "Não queremos estrangeiros. No

37 "O que seja propriamente o sebastianismo (...) eis o que não é talvez permitido desvendar." (PESSOA, 1978. p. 191).

38 “... uma das várias propostas de religião não-católica que obceca muitos republicanos de então (Sampaio Bruno, João de Barros, Jaime Cortesão, Aquilino Ribeiro, etc.)..." SARAIVA e LOPES, 1996. p. 965. 
sentimento patriótico não deve existir elemento que não seja nosso. Expulsemos pois o elemento romano. Se há que haver religião em nosso patriotismo, extraiamo-la desse mesmo patriotismo. Felizmente temo-la: o sebastianismo." 39 Por outra parte, no texto número 29 da série que analisamos, o qual inicia a segunda parte do volume Sobre Portugal, Pessoa refere um ritual sectário que teve como objetivo o túmulo de AlMotamide em Silves. Pessoa transcreve uma nota recebida na qual se explica que esse ritual é conseqüência de um acordo secreto entre um enviado do Concílio Pagão e os Mestres da Ordem Sebastianista. Desse acordo "era de esperar que, mais tarde ou mais cedo, houvesse de ser 'feita' uma 'animação' do espírito árabe, naquilo que era propriamente a transmissão do espírito pagão...” ${ }^{40}$

\begin{tabular}{|l|l|c|c|c|c|c|c|}
\hline \multicolumn{4}{|c|}{ NACIONAL } & \multicolumn{4}{c|}{ ANTI-NACIONAL } \\
\hline \multicolumn{2}{|c|}{ INDIVIDUAL } & \multicolumn{2}{c|}{ COLETIVO } & \multicolumn{2}{c|}{ INDIVIDUAL } & \multicolumn{2}{c|}{ COLETIVO } \\
\hline exotérico & esotérico & exotérico & esotérico & exotérico & esotérico & exotérico & esotérico \\
\hline $\begin{array}{l}\text { Pessoa } \\
\text { Regresso } \\
\text { Rei D. } \\
\text { Sebastião } \\
\text { Sebastião } \\
1888\end{array}$ & $\varnothing$ & $\begin{array}{l}\text { Sebastia- } \\
\text { nismo }\end{array}$ & Pombal & $\varnothing$ & $\begin{array}{l}\text { Catoli- } \\
\text { cismo }\end{array}$ & $\varnothing$ \\
Bandarra & \begin{tabular}{l} 
exmo \\
\hline
\end{tabular} & & & & & & \\
\hline
\end{tabular}

João Gaspar Simões (1996) - ao analisar o pensamento político manifestado por Pessoa nos artigos publicados em 1919 e 1920 no órgão nacionalista Acção, "Como organizar Portugal" e "A opinião pública" - o crítico salienta o papel de relevo que para Pessoa tem a língua no seu projeto político colectivo. Explica Simões:

... uno de los instintos hereditarios más generales entre los hombres, es el habla, puesto que el habla es una acción natural, general y constante en la que se traduce el vivir de la sociedad. De ahí deduce Fernado Pessoa que la lengua, estableciendo relaciones inmediatas entre los individuos, establece, al mismo tiempo, una relación de

\footnotetext{
${ }^{39}$ PESSOA, 1978. p. 179.

${ }^{40}$ PESSOA, 1978. p. 139.
} 
semejanza, gracias a la cual los hombres que hablan un mismo idioma se sienten hermanados en un mismo sentimiento o en un mismo instinto, el instinto de que pertenecen al mismo mundo, a una sociedad, a una misma patria. ${ }^{41}$

A questão da língua leva a considerar o problema das representações da linguagem no contexto das políticas implementadas e as idéias socialmente constituídas em torno de um idioma. ${ }^{42}$ No marco da didática da lingua e da literatura, tem lugar de destaque o tema das representações sociais e da linguagem. ${ }^{43}$ Neste sentido, Pessoa reproduz mas também contribui a conformar um imaginário de lingua portuguesa que entende esta como instrumento expressivo apto ao desenvolvimento de um império espiritual. A visão de Pessoa, neste terreno, é valorativa, em favor da preeminência da língua mais apta. Pessoa contrapõe dois campos, o espaço das línguas germânicas e o espaço das línguas latinas, pondo em destaque, em cada caso, o inglês e o português, respectivamente. "De tendência pertence em cada grupo destes a vitória cultural à língua mais capaz de exprimir, à mais rica não só em termos e frases, como também em capacidade de expressão, em riqueza gramatical, por assim dizer. Poder-se-á dizer nesta língua o que não pode dizer-se nas outras. ${ }^{44}$ Para Pessoa a riqueza lingüística baseia-se numa mestiçagem inicial: "Uma língua será tanto mais rica quanto mais a nação houver sido composta no seu início e fundação como tal, de elementos culturais diferentes." Neste sentido, a língua inglesa é a mais rica de todas as línguas européias, porque está composta do elemento latino e do elemento germânico. Por sua vez

${ }^{41}$ SIMÕES, 1996. p. 452.

${ }^{42}$ Cf. ARNOUX, Elvira Narvaja de e BEIN, Roberto. Prácticas y representaciones del lenguaje. Buenos Aires: Eudeba, 1999.

${ }^{4} 3$ Numa perspectiva sociolingüística um panorama da questão aparece em MATTHEY, Marinette. Representations sociales et langage. Les langues et leurs images. Neuchâtel: Institut de Recherches et Documentation Pédagogiques, 1997. p. 317-325. Na Argentina, a reflexão e a pesquisa em torno do ensino de línguas estrangeiras e seu imaginário pode-se avaliar em KLETT, Estela. Políticas lingüísticas en la universidad: el difícil camino de Babel. AA. VV. Politicas lingüisticas para América Latina. Buenos Aires: Facultad de Filosofía y Letras de la Universidad de Buenos Aires, 1999. p. 313-318.

${ }^{44}$ PESSOA, 1978. p. 228. 
o português, mais que o espanhol, segue-lhe em riqueza, já que se nutre do latim e do árabe. Neste confronto debate-se o próprio projeto de Pessoa escritor, na medida em que, formado em língua inglesa, criador poético relevante nessa língua, leva a cabo, em determinado momento, uma escolha patriótica, ao redor de 1907, para se transformar num poeta português. "A base da pátria é o idioma, porque o idioma é o pensamento em acção, e o homem é um animal pensante, e a acção é a essência da vida." ${ }^{5}$

\begin{tabular}{|c|c|}
\hline \multicolumn{2}{|c|}{ LÍNGUAS EM CONFLITO NA ÉPOCA MODERNA (ENTRE PARES) } \\
\hline $\begin{array}{c}\text { GRUPO DE LÍNGUAS DO NORTE } \\
\text { OU GERMÂNICAS }\end{array}$ & $\begin{array}{c}\text { GRUPO DE LÍNGUAS DO SUL } \\
\text { OU LATINAS }\end{array}$ \\
\hline INGLÊS & PORTUGUÊS \\
\hline $\begin{array}{l}\text { "O inglês, a língua mais rica da Europa pela } \\
\text { junção dos elementos 'anglo-saxões' com } \\
\text { os latinos, [...] naturalmente, enferma de } \\
\text { uma estructura do verbo relativamente } \\
\text { acanhada e que só com uma prolixidade de } \\
\text { emprego dos verbos auxiliares de certo } \\
\text { modo se redime." }\end{array}$ & $\begin{array}{c}\text { "Dais rica e a mais complexa." } \\
\text { mait }\end{array}$ \\
\hline
\end{tabular}

A política lingüistica de Pessoa implica uma série de elementos de amplo alcance, todos os quais conformam um programa completo de expansão cultural da língua em termos estritamente qualitativos. Em suas elaboração, podem-se reconhecer aspectos da distinção estabelecida por Dabène (1994 e 1997) entre um estatuto formal de lingua, aquele constituído pelo conjunto de disposições oficiais com caráter jurídico, que regulamentam o emprego e o ensino de línguas, e um estatuto informal de língua, isto é, o conjunto de imagens presentes no discurso corrente, sustentado pelos membros do corpo social. Este último desenha a imagem das línguas numa sociedade. O estatuto informal incide nas decisões dos atores sociais sobre a aprendizagem de línguas estrangeiras. Explica Dabène:

\footnotetext{
${ }^{45}$ PESSOA, 1978. p. 121.

46 PESSOA, 1978. p. 228.
} 
Il faut d'abord remarquer que ce statut n'est pas forcément toujours explicite: il peut arriver qu'il se manifeste de façon indirecte, biaisée: c'est le cas, pas exemple, de la décision prise par les parents en ce qui concerne le choix de la langue à apprendre par leur enfant lors de son parcours scolaire. Ce choix se fonde sur un certain nombre de raisons qui, pour n'être pas toujours exprimées ouvertement, n'en sont pas moins déterminantes." ${ }^{47}$

Dabène traça, com o fim de analisar o estatuto informal de lingua, cinco parâmetros, o critério econômico, o critério social, o critério cultural, o critério epistêmico e o critério afetivo. Os critérios lingüísticos de Pessoa para a constituição de um Império de Cultura são:

\begin{tabular}{|l|l|}
\hline \multicolumn{1}{|c|}{ PESSOA } & DABÈNE \\
\hline $\begin{array}{l}\text { “(1) Uma língua apta para isso, isto é: (a) } \\
\text { rica; (b) gramaticalmente completa; (c) } \\
\text { fortemente 'nacional'. (...) Complexidade } \\
\text { vocálica (mais que consonantal); a comple- }\end{array}$ & Critério epistêmico /Critério afetivo \\
xidade tónica (...)" & \\
\hline $\begin{array}{l}\text { "(2) O aparecimento de homens de génio } \\
\text { literário escrevendo nessa língua, e } \\
\text { ilustrando-a: (a) de génio de perfeição } \\
\text { lingüística; (c) [a concorrência de outros } \\
\text { factores culturais para o conteúdo dessas } \\
\text { obras de génio]." }\end{array}$ & Critério social / Critério cultural \\
\hline $\begin{array}{l}\text { "(3) A base material imperial para se poder } \\
\text { expandir (ainda mais) essa língua, e impó- } \\
\text { la. (Imposição material): número de gente } \\
\text { falando-a inicialmente; (b) extensão da } \\
\text { situação geográfica; (c) conquista e ocupa- } \\
\text { ção perfeita.” (PESSOA, 1978, p. 229) }\end{array}$ & Critério econômico / Critério social \\
\hline
\end{tabular}

${ }^{47}$ DABÈNE, 1997. p. 20. 
A questão da língua corresponde-se com a nação. Ela define esta última. Por isso, a nação deve assumir uma política de unificação da linguagem e, neste sentido, a aliança natural é com o Brasil. As correspondências dos três níveis traçados por Pessoa, a nação, o grupo civilizacional e a civilização, têm objetivos geopolíticos que relacionamse com temas freqüentemente debatidos na sociedade portuguesa: o Brasil "salvador" do século XVIII, o iberismo e a aliança secular com a Inglaterra. Mas, neste último caso, evidenciam-se as preocupações de Pessoa com o Imperialismo britânico, então hegemônico e concorrente. Num quadro de alianças, Pessoa traça um completo esquema geopolítico:

\begin{tabular}{|l|l|}
\hline \multicolumn{2}{|c|}{ LAÇOS CULTURAIS DA NAÇÃO PORTUGUESA } \\
\hline •NAÇÃO & $\begin{array}{l}\text { BRASIL: "Portugal, na determinação do apoio do seu } \\
\text { imperialismo cultural, tem que buscar, primeiro, o } \\
\text { Brasil, que tem por língua nacional o português." }\end{array}$ \\
\hline • GRUPO CIVILIZACIONAL & $\begin{array}{l}\text { IBÉRIA: "Portugal, na determinação do seu apoio em } \\
\text { grupo civilizacional, tem que buscar a Ibéria, de cuja } \\
\text { personalidade espiritual participa." }\end{array}$ \\
\hline CIVILIZAÇÃO & $\begin{array}{l}\text { INGLATERRA: "Portugal, na determinação do seu } \\
\text { apoio civilizacional, isto é, puramente político, tem } \\
\text { que buscar a Inglaterra (e os países de língua inglesa) } \\
\text { para apoio político da sua política externa." (PESSOA, } \\
\text { 1978, p. 233) }\end{array}$ \\
\hline
\end{tabular}

A maneira de raciocinar de Pessoa é, em grande medida, exemplo do que Umberto Eco (2000) chama "semiose bermética", ou seja, a prevalência do pensamento analógico de raiz mágica. ${ }^{48}$ A Cabala, a Numerologia e a Astrologia, entre outras vertentes do Ocultismo, constituem os componentes da operatória intelectual de leitura de Pessoa. ${ }^{49}$

${ }^{48}$ Cf. ECO, 2000. Segundo Eco a semiose hermética fundamenta as práticas teórico-críticas atuais reader-oriented.

${ }^{49}$ Cf. PESSOA, 1978. p. 192 e 193. 
A interpretação, que vai ler-se, não me pertence: nela tenho parte somente na redacção. Ignoro, por isso, por que processos se guiaram os seus intérpretes. Importa, de resto, saber tão-somente se a interpretação é certa, no que diz respeito ao pass[ad]o, aceitável no que diz respeito ao futuro." ${ }^{50}$

Eco analisa dois modelos de interpretação na tradição ocidental: o modelo racionalista e o modelo de metamorfose contínua. O primeiro, apoia-se nos princípios de identidade e não contradição. O segundo, na semelhança. Ambos os modelos confluem no pensamento hermético e na visão gnóstica do mundo que eclode a partir do século II. Paralelamente, além dos princípios de identidade e de não contradição, o Ocidente desenvolveu o critério de metamorfose contínua cujo símbolo foi HermesMercúrio, o deus volátil e ambíguo, pai das artes e protetor dos ladrões, mensageiro dos deuses, jovem e velho. "Como es abajo, asi es arriba. El universo se vuelve un gran teatro de espejos, donde cualquier cosa refleja y significa todas las demás." ${ }^{51}$ Esta concepção aparece num contexto de unidade e sincretismo sob o Império romano triunfante. Para o pensamento hermético, a linguagem deve ser ambígua, polivalente e metafórica para nomear a Unidade que reúne todos os opostos. Não obstante, na procura de um sentido último, aceita-se um deslizamento infinito do sentido. Anota Pessoa: "Deus escreve direito por linhas tortas" 52 e agrega: "A inteligência analógica, cujo grau ínfimo é a citação e a alusão, com que se tanto ilustra o discurso, e cujo grau maior é (a interpretação das) profecias e dos símbolos. A interpretação das profecias é uma fusão da inteligência analógica com a racional (fenómeno sincrético!)." ${ }^{53}$ Nos limites do pensamento analógico, um vegetal, por exemplo, não é definido por suas características ou função, senão por ser parecido com algum objeto, órgão ou elemento. A forma do vegetal pode lembrar a forma de um órgão do corpo humano e, por sua vez, por associação analógica, corresponder-se com um signo zodiacal cuja regência representa um bicho, um elemento da natureza, uma qualidade psicológica, uma pedra e assim por diante. "El pensamiento hermético, explica Eco, transforma todo el teatro del mundo en fenómeno lingüístico

\footnotetext{
${ }^{50}$ PESSOA, 1978. p. 176.

${ }^{51}$ ECO, 2000. p. 53.

52 PESSOA, 1978. p. 178.

53 PESSOA, 1978. p. 186.
} 
y, al mismo tiempo, sustrae al lenguaje todo el poder comunicativo." ${ }^{54} \mathrm{Em}$ várias passagens da série de textos que analisamos, Pessoa refere-se à leitura analógico-hermética: "Assim como a inteligência dialéctica, que tem nome razão, domina e compõe todos os elementos, com que se forma o conhecimento científico, assim também a inteligência analógica, que não tem nome especial, domina e compõe todos os elementos de que se forma o conhecimento oculto." 55 Unem-se segredo e conjura, segredo cósmico e segredo político. Pessoa escreveu:

No Terceiro Corpo das suas Profecias, o Bandarra anuncia o Regresso de D. Sebastião (pouco importa agora o que ele entende por esse 'regresso') para um dos anos entre 1878 e 1888 . Ora, neste último ano $(1888)^{56}$ deuse em Portugal o acontecimento mais importante da sua vida nacional desde as descobertas: contudo, pela própria natureza do acontecimento, ele passou e tinha de passar inteiramente despercebido. ${ }^{57}$

Pessoa atribui a interpretação do Terceiro Corpo das Trovas de Bandarra a duas personagens que intuímos tratar-se de outros dois heterônimos saídos de seu fértil universo discursivo, Raphael Baldaya e Hermes Stella. A propósito da quadra que diz: "Augurai, gentes vindouras,/ Que o rei, que de aqui há-de ir,/ Vos há-de tornar a vir/ Passadas trinta tesouras." Pessoa anota: "Sabedores que a interpretação profética é sempre tripla, temos aqui três cousas, a que aplicar o triplo sentido: o 'rei que de aqui há-de ir', o 'tornar a vir', e as 'trinta tesouras." 58 Com base nesta tríplice leitura, Pessoa deduz, no trecho 54, poder-se determinar três datas, segundo Stella,1640, 1733 e 1888. Segundo Baldaya 1578, 1728 e 1878. Os anos tratam da perda da independência, da restauração bragantina, da aparição do Marquês de Pombal e do nascimento de Pessoa. ${ }^{59}$

${ }^{54}$ ECO, 2000. p. 54.

55 PESSOA, 1978. p. 183.

${ }^{56}$ Joel Serrão lembra que 1888 é o ano de nascimento de Pessoa.

57 PESSOA, 1978. p. 174.

58 PESSOA, 1978. p. 180.

${ }^{59}$ Cf. PESSOA, 1978. p. 180-1. As enigmáticas anotações nas margens que Pessoa fez ao Terceiro Corpo das Trovas (fragmento 44), pletóricas de cálculos cabalísticos e numerológicos, de sentido oculto, se interpretam coerentemente nesta direção. V. SERRÃO, Joel. A busca pessoana do sentido de Portugal. Pessoa 1978. p. 6-63. 


\section{Conclusões}

O posicionamento de Pessoa levaria a considerar a pertinência das forças espirituais na constituição de um projeto nacionalista: "Quem não tem a consciência certa das raízes profundas do seu ser, isto é, do povo a que pertence, de que coisa pode ter certeza ou noção?" ${ }^{60}$

Em primeiro lugar, é preciso lembrar que qualquer nacionalismo é uma construção da ordem do imaginário e que, enquanto construção discursiva, carece de propriedades essenciais ou intrínsecas. A nação não denota mundo externo e referencial senão referente simbólico, o que Anderson (1993) chamou "comunidade imaginada". Uma entidade sustentada e alimentada por uma série de instituições discursivas, literatura nacional, idioma, imprensa periódica, programas educativos. A constituição no indivíduo de um sentido de pertencer à "comunidade imaginada" pode ser mais ou menos solidário com o resto de seus compatriotas e o grau de ajuste é causa de sucesso ou fracasso na consecução dos projetos pessoais. Esses projetos, representados pela literatura, apoiando-se em discursos nacionalistas, por sua vez retomam as vozes da polêmica social e contribuem a conformar imagens de nação. Neste sentido, o nacionalismo de Pessoa é produto de uma prática de semiose hermética muito característica das soluções de extrema direita. ${ }^{61}$ Em relação à profecia, especialmente do Terceiro Corpo das Trovas, Pessoa adquire um compromisso mitogênico. Ele catalisa, em seu próprio imaginário, o imaginário coletivo ao tempo que refunda um conceito poético de nação portuguesa. Os principais pontos são: preeminência do divino na alma portuguesa, libertação do nacionalismo de agregados espúrios, proposta de Bandarra como patrono do país e exaltação do português como a mais rica e complexa das línguas latinas. ${ }^{62}$

${ }^{60}$ PESSOA, 1978. p. 89.

${ }^{61}$ Nos círculos políticos de direita na Argentina, por exemplo, é muito freqüente reivindicar as profecias de Dom Orione, Juan Perón ou quem é conhecido como o "Nostradamus argentino", o artista plástico Benjamín Solari Parravicini. V. Adolfo de Obieta. Tiempos de profecías III. Profecías siglo XX. Buenos Aires: Corregidor, 1998.

${ }^{62}$ Talvez, no momento atual, aquilo que, do projeto político de Pessoa, poderia aparecer para alguns como mais interessante, - rejeitados por inadmissíveis 
Em segundo lugar, é necessário sublinhar que o nacionalismo de Pessoa leva a marca de uma leitura com base popular. Implicamos na palavra leitura o distanciamento e a recuperação de uma ou várias fontes. ${ }^{63}$ Quando se refere ao seus modelos próximos, Pessoa marca essa diferença entre a leitura de um mito vivo e a tradição: “... cairam os intregralistas franceses e portugueses no erro tradicionalista, confundindo tradição com carácter nacional, isto é, confundindo as cristalizações desse carácter ..." Embora seja emergência de uma ideologia modernista muito característica da Europa posterior à Primeira Guerra Mundial, o nacionalismo de Pessoa participa dum ideário popular português. Pessoa baseou-se num corpus poético popular, próprio da língua portuguesa, as Trovas de Bandarra e no seu correlato, a mitologia sebastianista: "Temos, felizmente, o mito sebastianista, com raízes profundas no passado e na alma portuguesa. Nosso trabalho é pois mais fácil: não temos que criar um mito, senão que renoválo." ${ }^{65}$ Ainda sendo, o projeto individual de um nacionalista nostálgico e "saudosista", constitui um programa ideológico coletivo, cujo suporte é o princípio de crença baseado na preeminência da língua portuguesa, o

os seus postulados antidemocráticos - é precisamente a afirmação local ou nacional num contexto de problemática e falaz globalização. Esse fenômeno do localismo poderia ser definido assim: "O que a pós-modernidade procura de um lado cancelar - os nacionalismos e as identidades perenes - é exatamente aquilo que, na mesma pós-modernidade, se descreve como localismo, ressurgência da mentalidade paroquial das cidades-estado definidas por muralhas que separavam rigidamente o interior do exterior e que vem à tona na forma trágica dos conflitos étnicos atuais." Teixeira Coelho. Dicionário crítico de política cultural. Cultura e imaginário. 2. ed. São Paulo: Iluminuras, 1999. p. 243.

63 "Au plan sémantique, je m'inscris du cotê de ceux pour qui sens et altération sont indissociablement liés dans le cadre d'une sémantique de l'alteration. Cela signifique que le sens jaillit là ou 'il y a altération, là où il se transforme pour devenir autre. (...) De ce point de vue, la lecture est l'exemple même d'un processus à travers lequel le sens devient autre. Toute lecture est par définition altération." SOUCHON, Marc. La lecture-compréhension de textes: aspects théoriques et didactiques. Revue de la SAPFESU, Buenos Aires, numero hors série p. 23, 1997.

${ }^{64}$ PESSOA, 1978. p. 200.

65 PESSOA, 1978. p. 255. 
destino imperial português e a realização do messiânico Quinto Império, de ressonâncias sebásticas. Por sua vez, feito um demiurgo social surgido da elite visando ao povo, segundo a classificação de Burucúa, recria uma leitura tradicional ao jeito do modernismo, na qual um Bandarra coletivo relaciona-se com a heteronímia. Nesse sentido, existe em Pessoa íntima relação entre os conceitos de língua portuguesa, semiose hermética e nação. Os conteúdos exclusivamente nacionais das Trovas só poderiam ter-se expressado em português, da mesma maneira que uma leitura ocultista só poderia resgatar esses conteúdos na própria língua nacional. A tríplice relação lingua, império e sebastianismo territorializa, na disposição das Trovas, por seu irredutível caráter nacional, a mera construção imaginária da pátria, em contraposição histórica com o inglês. Repare-se que Pessoa avalia as línguas por sua riqueza cultural e étnica, produto da mestiçagem. É como se o aluvião e o entrelaçamento dos componentes culturais agissem como no caso do Terceiro Corpo das Trovas, que ficam legitimadas no momento em que são concebidas como obra da comunidade nacional. Como pano de fundo, um certo ideal vitalista renitente a qualquer estagnação. Ao contrário dos tradicionalistas, e nisto é bem moderno, apoia uma regeneração profunda e dinâmica de Portugal, visando ao futuro. Pessoa propõe criar "um Imperialismo andrógino, reunidor das qualidades masculinas e femininas: imperialismo que seja cheio de todas as subtilezas do domínio feminino e de todas as forças e estruturações do domínio masculino." E a seguir agrega: "Realizemos Apolo espiritualmente." ${ }_{6}$

Por último, seria justo salientar que Pessoa procurou, com patriotismo, nesse processo de resgate popular, uma saída política para seu país no domínio da cultura. Pessoa declarou: "Criando uma civilização espiritual própria, subjugaremos todos os povos; porque contra as artes e as forças do espírito não há resistência possível, sobretudo quando elas sejam bem organizadas, fortificadas por almas de generais do Espírito." ${ }^{" 67}$ Objetivamente, levando em consideração a situação de Portugal no rígido contexto do Imperialismo, o caminho traçado por Pessoa tem sua própria lógica, mais ainda se se leva em consideração, inclusive por causa disso, esse jeito alienado da própria solução ocultista. Assim é que aparece um dos poucos destinos possíveis perante as demais nações colonialistas do

${ }^{66}$ PESSOA, 1978. p. 226.

${ }^{67}$ PESSOA, 1978. p. 226. 
mundo, especialmente a Inglaterra: "Só pode realizar o Império Espiritual a nação que for pequena, e em que, portanto, nenhuma tentativa de absorção territorial pode nascer, com o crescimento do ideal nacional, vindo por fim a desvirtuar e desviar do seu destino espiritual o original imperialismo psíquico." ${ }^{18}$

\section{Referências Bibliográficas}

AA. VV. Sobre as naus da iniciação. Estudos portugueses de literatura e história. São Paulo: Unesp, 1998.

ANDERSON, Benedict. Comunidades imaginadas. Reflexiones sobre el origen y la difusión del nacionalismo. Trad. E. Suárez. México: Fondo de Cultura Económica, 1993.

BESSELAAR, José van den. As Trovas de Bandarra. ICALP Revista, Lisboa, n.4, p.14-30, mar. 1986.

BURKE, Peter. La cultura popular en la Europa moderna. Madrid: Alianza, 1996.

BURUCÚA, José Emilio. Corderos y elefantes. La sacralidad y la risa en la modernidad clásica - siglos XV a XVII. Buenos Aires: Universidad de Buenos Aires/Miño y Dávila, 2001.

DABÈNE, Louise. Repères sociolinguistiques pour l'enseignement des langues. Paris: Hachette, 1994.

DABÈNE, Louise. L'image des langues et leur apprentissage.Marinette Matthey (Coord.). Les langues e leurs images. Neuchâtel: Institut de Recherches et Documentation Pédagogiques, 1997. p. 19-23.

ECO, Umberto. Los limites de la interpretación. Trad. H. Lozano. Barcelona: Lumen, 2000.

PESSOA, Fernando. Sobre Portugal. Introdução ao problema nacional. Selecção de textos $M^{\underline{a}}$ I. Rocheta e M ${ }^{a}$ P. Morão, introdução e organização Joel Serrão. Lisboa: Ática. 1978.

PESSOA, Fernando. Poesia profética, mágica e espiritual. Edição de Pedro Teixeira da Mota. Lisboa: Manuel Lencastre, 1989

${ }^{68}$ PESSOA, 1978. p. 225. 
REAL, Miguel. Portugal. Ser e representação. Lisboa: Difel, 1998.

SARAIVA, António José e LOPES, Óscar. História da Literatura de Portuguesa. 17. ed. Porto: Porto, 1996.

SERRÃO, Joel. Fernado Pessoa, cidadão do imaginário. Lisboa: Horizonte, 1981.

SIMÕES, João Gaspar. Vida y obra de Fernando Pessoa. Historia de una generación. Trad. F. Cervantes. México: FCE, 1996.

VIEIRA, António. De Profecia e Inquisição. Brasília: Senado Federal, 1998, Coleção Brasil 500 anos.

\section{Resumo}

O nacionalismo de Pessoa, embora seja emergência de uma ideologia modernista muito característica da Europa posterior à Primeira Guerra Mundial, participa da cultura nacional portuguesa e, mesmo sendo o projeto solitário de um nacionalista saudosista, constitui um programa ideológico coletivo. Em consonância com o seu ideário conservador, antidemocrático e monárquico, tenta uma formulação nacionalista ancorada no passado português, a mística esotérica e a messiânica popular. Pessoa político é, neste sentido, leitor principal de Bandarra e, por sua vez, leitor de um gênero específico de literatura popular, a profecia. O projeto pessoano tem, como suporte, o princípio de preeminência da língua portuguesa e dos destinos de um Quinto Império espiritual para Portugal.

\section{Abstract}

Pessoa's nationalism participates in the Portuguese national culture although it is the emergency of a modernist ideology very characteristic of after First World War Europe. It constitutes a collective ideological program although it is the solitary project of a "saudosista" nationalist. In consonance with his conservative, anti-democratic and monarchic ideational system, he tries a nationalist formulation anchored in the Portuguese past, the occult mystic and the popular messianic tradition. The politician Pessoa is, in this sense, a reader of Bandarra and, at the same time, reader of a specific genre of popular literature: the prophecy. The pessoan project has, as support, the rule of pre-eminence of the Portuguese language and of the destinies of a spiritual Fifth Empire for Portugal. 